\title{
Muscle Dysmorphia and Personality Trait: A Significant Link in Bodybuilders
}

\author{
Jaspal Singh Sandhu, Sai Kishore, Shweta Shenoy, Harwinder Singh Randhawa
}

\begin{abstract}
The purpose of this study was to test for significant link between personality trait and muscle dysmorphia in bodybuilders. A total of 212 bodybuilders filled the muscle dysmorphia inventory of which $44.3 \%(n=94)$ were found to be muscle dysmorphic. Their personality traits assessed using eysenck personality profiler in the vienna testing system machine revealed $65 \%$ of muscle dysmorphic bodybuilders being predominantly oriented toward extroversion type of personality. Further statistical analysis revealed, the significance between the muscle dysmorphia inventory and the personality traits and its results are discussed. Estimating the prevalence and categorizing based on personality has rather opened a new gateway to identify such vulnerable men who are susceptible to their own drive for muscularity.
\end{abstract}

Keywords: Muscle dysmorphia, Personality, Bodybuilders.

How to cite this article: Sandhu JS, Kishore S, Shenoy S, Randhawa HS. Muscle Dysmorphia and Personality Trait: A Significant Link in Bodybuilders. J Postgrad Med Edu Res 2013; 47(2):77-82.

\section{Source of support: Nil}

Conflict of interest: None declared

\section{INTRODUCTION}

Men obsessed with a drive for muscularity or in better word an ideal body image, in which bodybuilders being more susceptible ${ }^{1,2}$ are often at risk for developing body dysmorphic disorders (BDD) like muscle dysmorphia (MD). Such vulnerable men passionate with their body and image think of being superman like, invincible, ${ }^{3}$ sometimes even unattractive or monstrous. ${ }^{4} \mathrm{MD}$ also known as reverse anorexia nervosa, ${ }^{5}$ is characterized by a chronic preoccupation that one is insufficiently muscular (or sometimes, especially in the case of women, both muscular and lean). ${ }^{6}$ The body building populations were reported to be majorly affected by this BDD. ${ }^{4-6}$ These are the men who obviously have the desire to look more muscular than the others thriving hard to achieve a Herculean physique. A compulsive need to maintain a strict workout and diet schedule $^{7}$ makes these men to miss important social or family events, stick to a strict exercise schedule, hide their physique from others, which are considered as characteristic features of MD. ${ }^{8}$ Also there is a preoccupation in them of not being identical as others, and of being small or not enough muscular. ${ }^{9}$

Preoccupation defined as an extreme or excessive concern, ${ }^{10}$ is nevertheless ascribed to social factors, where body image itself is a psychological phenomenon significantly affected by social factors. ${ }^{11}$ One of the primordial social factors being the exposure to magazines and movies. ${ }^{12}$ Films do make an impact on the mind leading to imagine a larger than life portrait, causing frequent evaluation of one's body to gain information about size, shape or weight. ${ }^{13}$ It is the concept of learned behavior that the media projects in viewer's mind, ${ }^{14}$ where the mental image drawn in the mind is harder to prevail over. Men with MD were even thought to have psychiatric conditions. ${ }^{15}$ Further, there is an evidence of BDD being associated with Type D personality ${ }^{16}$ which necessitates the need for personality to be assessed in the context of bodybuilders affected with MD.

The main idea of this study is to test for any significance between personality trait and MD in bodybuilders. Since, various personality questionnaires have been tested on men with an obsession for muscularity, ${ }^{17}$ we used the Eysenck's Personality Profiler (EPP6) in the vienna testing system (VTS) machine which is based on the personality theory comprising extraversion (E), adventurousness/psychoticism (P) and emotionality/neuroticism (N), proposed by Eysenck. There are rich evidence's about the E, P, N model of Eysenck's personality theory. ${ }^{18,19}$ and the pathological preoccupation developed, ${ }^{6,20}$ yet it is important to establish a statistical data in our country. With the given popularity of the Indian films and its viewership, evidence of Indian men and their liking for films that portrays supernatural talents ${ }^{21}$ was anticipated. Considering this Indian scenario, we hypothesized that the muscle dysmorphic bodybuilders would be more oriented toward one particular personality trait with which a significant link is possible.

\section{MATERIALS AND METHODS}

\section{Participants}

Data's were collected in India. A total of 212 male bodybuilders participated in the study, of which 149 bodybuilders were from the city of Amritsar, Punjab and 63 bodybuilders were from Chennai, Tamil Nadu. Of these, 94 bodybuilders were found to be symptomatic to MD with an age limit of 18 to 34 years and mean age being $23.31 \pm$ 3.64. In our study, both recreational and professional bodybuilders were included and all the bodybuilders were selfidentified. There was no definite criteria to identify the 
recreational bodybuilders, as they were bound to exercise only on their own will either as a pass time activity or simply to gain or reduce weight and were intended to continue their exercises regularly. The professional bodybuilders were mostly the gym trainers who exercise regularly and who had a minimum of one stage appearance. The data's of bodybuilders were taken in a large scale, with an informed consent being supplied to each participant and detailed instruction about the study was explained prior to the commencement of the procedure.

\section{Procedure}

A 6-factor 27-item muscle dysmorphia inventory (MDI) 22,23 questionnaire was used to identify the symptomatic bodybuilders. Rhea et al in 2004, classified the MDI with its 6 subscales of 'diet', 'supplement', 'physique', 'exercise dependence', 'size and symmetry' and 'pharmacology' under a unique scoring system with specified cutoff scores. The cutoff scores determined the level of MD. The higher the score is the more symptomatic one is toward MD. The MDI has self-explanatory questions like, 'how many hours do you exercise in a day'; 'what is your diet pattern like'; 'do you take energy supplements prior to or after exercises'; 'do you use steroids or other drugs', that was spread through its 6 subscales. Irrespective of all these factors the participants were seen on the whole as 'bodybuilders' and the data was narrowed and concerned toward analysis of their personality alone. This 'zeroing' of data toward the personality led us to new dimensions of bodybuilders symptomatic to MD which was recorded using the VTS.

VTS is a computerized psychological diagnostic instrument designed by Schuhfried, Austria. The eysenck personality profiler version 6 (EPP6) was used for assessment of personality of the muscle dysmorphic bodybuilders. The shorter version of EPP6 which had a total of 200 items/questions divided among 9 subscales, three each under E, P and N respectively was used. Activity, sociability and assertiveness were categorized under extroversion (E); inferiority, unhappiness and anxiety under emotionality (N) while risk-taking, impulsiveness and irresponsibility belonged to adventurousness (P) type of personality trait. However, the overall raw score that came out upon test completion was considered for evaluation. All the 200 questions were of 'yes' or 'no' type and were selfexplanatory. There were secondary variables, such as 'dissimulation' which showed the level of openness of an individual. An increase in the dissimulation score indicated decrease in the reliability of the questionnaire. Hence, a result with a high dissimulation of more than a score of 25 was not considered for the study. Almost 27 participants were neglected from the study as a result of high dissimulation and those data's were redone. Similarly, there were 'cannot decide’ answers for which the participant could not answer. More than $10 \%$ of the questions for which 'cannot decide' is answered is again considered to decrease the reliability of the questionnaire. Therefore, those results were also neglected. Since, there was only one participant to answer more than $10 \%$ of 'cannot decide', that data was also redone with another participant. As dissimulation and number of 'cannot decide' were considered to be secondary variables, they were not considered for statistical evaluation.

\section{STATISTICAL ANALYSIS}

Statistical analysis was done using the statistical package for social science (SPSS) version 17. The data's were categorized based on the three personality traits and crosstab was used to identify the percentage of the three personality traits in relation to the MDI. One statistically significant data was found in the supplement subscale of the MDI.

\section{RESULTS}

Our primary objective was to find any significant link between MD and personality trait, but VTS also helped us in estimating the prevalence of MD in the Indian bodybuilders. Of the 212 bodybuilders participated in the study, 100 bodybuilders were found symptomatic based on the MDI and the prevalence of MD in Indian bodybuilders was estimated to be $47.1 \%$. However, only 94 bodybuilders (44.3\%) were considered for this study. There were six subjects who scored identically in two personality traits and hence they could be considered to be oriented toward both the personalities. Two participants showed signs of both extraversion-emotionality; 3 were found to be extraversionadventurousness; and 1 participant was adventurousemotional. As all these six participants were associated with more than one personality trait they were excluded from the study. Thus VTS results revealed that the bodybuilders symptomatic to MD are more oriented toward extraversion (65\%) type of personality. Also, 21\% of bodybuilders were found to be emotional than the $13 \%$ of adventurous (Fig. 1).

Considering the predominance of extraversion trait over the other personality traits (Table 1 ) it was evident that the extraverts were more fond of using supplements, as we achieved one statistically significant data $(p<0.05)$ in the supplement subscale. Supplement intake does make a significant contribution in building body, yet is not the elixir to every bodybuilder. Apt focus was given to exercises and diet too. The size and symmetry subscale is a mandatory and was taken as a constant; hence it showed $100 \%$ result 
and was not considered as part of evaluation. The pharmacology subscale was excluded as almost 61 of the 94 participants accepted that they have never used performance enhancing substances such as steroids.

\section{DISCUSSION}

This study differed from previous researches done on MD. Firstly, because the psychological profiling done was completely objective and it involved computerized diagnostics. The results obtained are free from bias as the software automatically generated raw scores upon test completion, making it highly reliable. Though, earlier researches have been carried out on personality, its impact on exercises ${ }^{24}$ and body dissatisfaction, ${ }^{25}$ to our knowledge this is the only study being carried on the personality of bodybuilders who are symptomatic to MD. The study offers support to use personality as a criterion in identifying individuals symptomatic to MD.

MD has recently been proposed as a new disorder addressing the pathological pursuit of hypermesomorphic physique. ${ }^{22}$ Many studies have stated that the prevalence

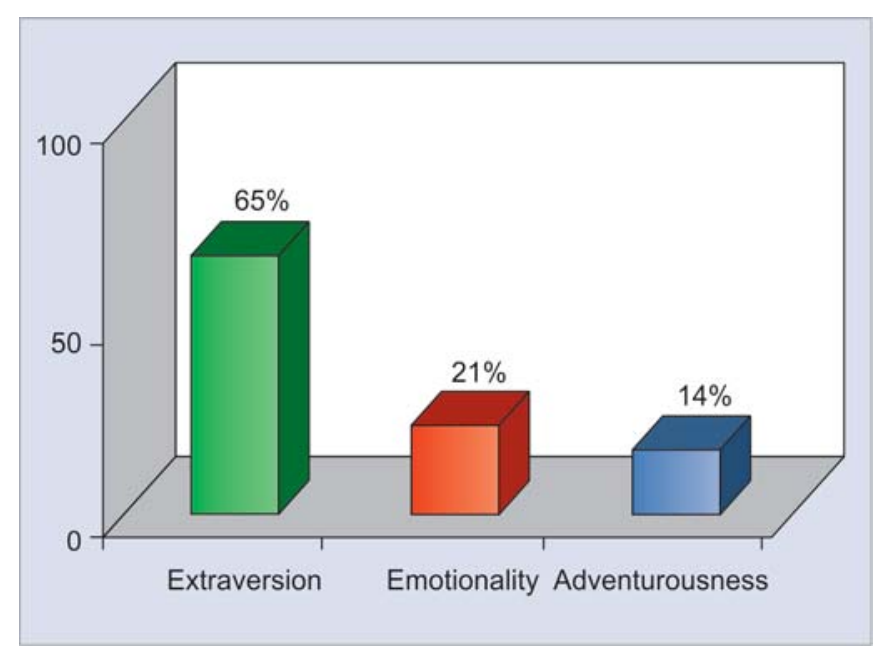

Fig. 1: Total percentage of the three personality traits of MD is either not known ${ }^{26-28}$ or difficult to calculate. ${ }^{29}$ Also, Choi et al (2002) concluded that there are no prevalence estimates of MD owing to lack of epidemiological studies. ${ }^{30}$ However, Hitzeroth et al (2001) reported a prevalence of $53.6 \%$ in their study ${ }^{31}$ and Behar and Molinari (2010) reported a $13.6 \%$ prevalence of MD in weight lifters. ${ }^{32}$ Though our study reports a prevalence of $47.1 \%$ in the bodybuilding population, this was precisely concerned to the two demographic regions we surveyed. We do believe that the prevalence of MD is difficult to estimate, yet not impossible, as targeted population, such as bodybuilders are widespread always. As observed by HG Pope et al in 1997, it is important to note that MD should not be confused with mere enthusiasm for bodybuilding. Many people may become so devoted to bodybuilding or other sports that they sometimes forego other opportunities. However, ordinary dedication to sport is not associated with profound dissatisfaction once preoccupation sets in. ${ }^{6}$

To identify this preoccupation, personality appeared to be an effective tool for us. We hypothesized that bodybuilders symptomatic to MD would be oriented toward one particular personality, and extraverts were found to be abundant in it. Extraversion is predicted upon the biological basis of personality ${ }^{18}$ which is attributed to cortical arousal mechanism in the central nervous system. ${ }^{33}$ Even though extroversion was predominant in our results, the difference between the other two traits was less. The bodybuilders, who were known to perform rough and tough exercises, did expose their emotional side too. Emotionality needs to be addressed with caution where, even depression can lead to body image. ${ }^{34}$ However, lower scores in emotionality are consistent with the evidence that regular exercise reduces the anxiety level. ${ }^{35}$ Though they scored less on emotionality still the emotional content is noteworthy. Considering the scores, if a participant has an overall raw score of 33 in extraversion; 10 in emotionality and 27 in adventurousness, we can say that this person is predominantly inclined toward

\begin{tabular}{lccc}
\multicolumn{4}{c}{ Table 1: The statistical significance of the MDI subscales } \\
\hline Variables & Extraversion & Adventurousness & Emotionality \\
\hline Diet & & & \\
Pearson Chi-square & 0.200 & 0.292 & 0.004 \\
Asymp. significance & 0.655 & 0.589 & 0.947 \\
Supplement & & & 3.202 \\
Pearson Chi-square & 4.857 & 0.857 & 0.074 \\
Asymp. significance & $0.028^{*}$ & 0.355 & 1.339 \\
Physique & & & 0.247 \\
Pearson Chi-square & 2.470 & 0.642 & \\
Asymp. significance & 0.116 & 0.423 & 0.672 \\
Exercise dependence & & & 0.412 \\
Pearson Chi-square & 0.558 & 0.004 & \\
Asymp. significance & 0.455 & 0.952 & \\
\hline
\end{tabular}

*Indicates that the data is significant at $p<0.05$ 
extraversion type of personality trait. Similarly, we conclude that the $65 \%$ of the bodybuilders who were found to be extroverts were predominantly inclined toward extraversion. The remaining 35\% are not considered to be extroverts, as either they exhibited less proximity toward extraversion or predominated by the other two personality traits.

Young men who are dissatisfied with their body shape and musculature are likely to turn to bodybuilding, dietary supplements and anabolic steroids to maintain their body in shape. ${ }^{36}$ This became evident in the significance we found between the two questionnaires. It revealed the exact percentage distribution of the three personality traits toward each of the MDI subscales. Significant result was observed among the extroverts in the supplement subscale where $50.8 \%$ of the extrovert bodybuilders were fond of using supplements to enhance their exercise performance (Table 2). Though the focus was majorly on supplements, the preference given to the exercise dependence and diet was also exposed. There is enough evidence that exercise dependence can significantly enhance self-esteem where people begin bodybuilding because of poor body image and low self esteem. ${ }^{37}$ The importance of Indian diet pattern has been well-assessed through earlier studies ${ }^{38,39}$ and our study revealed it precisely (Table 2). Hence, it is now perceptible that the muscle dysmorphic bodybuilders are more reliant on these performance enhancing methods and this study highlights the same.

\section{LIMITATIONS}

There are a few possible limitations in this study. Given the two demographic regions we surveyed, it is an unimpeachable fact that $\mathrm{MD}$ is prevalent in our country. However, these two regions alone cannot represent the bodybuilding population of the whole country, as India being the world's largest democracy, might offer a whole new data if the same study is repeated on a larger scale. Earlier researches have proved that BDD belongs to a category of DSM-IV disorders. ${ }^{8,40}$ Even though our research was related to psychology, we succinctly concentrated only on the personality aspect alone. Studies have proved that the reliability of the $\mathrm{MDI}^{7,22,23}$ and $\mathrm{EPP}^{41,42}$ are unquestionable. Yet, the MDI can only show how much an individual is prone to symptoms of MD and considering it as a diagnostic tool requires in depth evaluations. Similarly, the personality types distinguished by the EPP6 can show how much an individual is oriented toward that particular personality trait. Same implications being made on an even larger sample size with MD occupying the center stage may provide effective understanding of this type of BDD.

\section{CONCLUSION}

This study was aimed to find a significant link between personality trait and MD in bodybuilders. The reported prevalence in this study is a substantial evidence for the presence of such psychopathologies. The VTS showed the predominance of extraversion, yet the other two personality traits are not a fact to be overlooked. There is a dogma called 'body image' that surrounds the bodybuilding population which needs deeper evaluation. Though the bodybuilders were found to be affected by MD, yet they alone cannot be considered as the targeted population. If MD is associated with an obsession for better physique where bodybuilders being the most affected, identifying their personality does no harm to it. It has rather opened a new view point where future studies may reveal broader aspects of personality of the muscle dysmorphics and results are subjected to change.

\begin{tabular}{|c|c|c|c|c|c|c|}
\hline \multirow[t]{2}{*}{ Variables } & \multicolumn{2}{|c|}{ Extraversion } & \multicolumn{2}{|c|}{ Emotionality } & \multicolumn{2}{|c|}{ Adventurousness } \\
\hline & $\begin{array}{l}\text { Yes }(\%) \\
(n=61)\end{array}$ & $\begin{array}{l}\text { No }(\%) \\
(n=33)\end{array}$ & $\begin{array}{l}\text { Yes }(\%) \\
(n=20)\end{array}$ & $\begin{array}{l}\text { No }(\%) \\
(n=74)\end{array}$ & $\begin{array}{l}\text { Yes (\%) } \\
(n=13)\end{array}$ & $\begin{array}{l}\text { No }(\%) \\
(n=81)\end{array}$ \\
\hline $\begin{array}{l}\text { Diet subscale (cutoff }=25) \\
\text { with mean } \pm S D\end{array}$ & $\begin{array}{l}66.7 \% \\
23.36 \pm 3.78\end{array}$ & $\begin{array}{l}57.6 \% \\
23.52 \pm 3.46\end{array}$ & $\begin{array}{l}60.0 \% \\
24.30 \pm 2.45\end{array}$ & $\begin{array}{l}60.8 \% \\
23.18 \pm 3.89\end{array}$ & $\begin{array}{l}53.8 \% \\
22.31 \pm 4.46\end{array}$ & $\begin{array}{l}61.7 \% \\
23.59 \pm 3.51\end{array}$ \\
\hline $\begin{array}{l}\text { Supplement subscale (cutoff }=20 \text { ) } \\
\text { with mean } \pm \text { SD }\end{array}$ & $\begin{array}{l}50.8 \% \%^{* \star} \\
16.95 \pm 4.61\end{array}$ & $\begin{array}{l}27.3 \% \\
15.58 \pm 4.09\end{array}$ & $\begin{array}{l}25.0 \% \\
15.75 \pm 3.93\end{array}$ & $\begin{array}{l}47.3 \% \\
16.66 \pm 4.60\end{array}$ & $\begin{array}{l}30.8 \% \\
15.31 \pm 4.47\end{array}$ & $\begin{array}{l}44.4 \% \\
16.65 \pm 4.46\end{array}$ \\
\hline $\begin{array}{l}\text { Physique subscale (cutoff }=30 \text { ) } \\
\text { with mean } \pm \text { SD }\end{array}$ & $\begin{array}{l}37.7 \% \\
25.51 \pm 6.03\end{array}$ & $\begin{array}{l}54.5 \% \\
26.61 \pm 6.52\end{array}$ & $\begin{array}{l}55.0 \% \\
27.65 \pm 6.01\end{array}$ & $\begin{array}{l}40.5 \% \\
25.42 \pm 6.20\end{array}$ & $\begin{array}{l}53.8 \% \\
25.00 \pm 7.20\end{array}$ & $\begin{array}{l}42.0 \% \\
26.04 \pm 6.06\end{array}$ \\
\hline $\begin{array}{l}\text { Exercise dependence subscale } \\
\text { (cutoff }=20 \text { ) } \\
\text { with mean } \pm \text { SD }\end{array}$ & $\begin{array}{l}82.0 \% \\
20.07 \pm 2.58\end{array}$ & $\begin{array}{l}87.9 \% \\
21.21 \pm 2.31\end{array}$ & $\begin{array}{l}90.0 \% \\
21.45 \pm 2.03\end{array}$ & $\begin{array}{l}82.4 \% \\
20.78 \pm 2.59\end{array}$ & $\begin{array}{l}84.6 \% \\
20.85 \pm 2.73\end{array}$ & $\begin{array}{l}84.0 \% \\
20.94 \pm 2.46\end{array}$ \\
\hline
\end{tabular}

**That out of 61 persons with extroversion more (50.8\%) had supplement subscale $\geq 20$ as compared to those with less extroversion $(n=33)$ where only $27.3 \%$ had supplement subscale $\geq 20(p=0.028)$. Note: Each of the three personality traits were categorized based on the scores obtained. Example, in extraversion yes $(n=61)$ denotes that out of the total 94 muscle dysmorphic bodybuilders 61 were extroverts. The remaining 33 were not considered as extroverts as they exhibit less characteristics of extraversion due to the predominance of the remaining two personality traits. 


\section{REFERENCES}

1. Olivardia R, Pope HG Jr, Borowieckie JJ III, Cohane GH. Biceps and body image: The relationship between muscularity and self esteem, depression and eating disorder symptoms. Psychology Men Masculinity 2004;5(2):112-20.

2. Jankauskiene R, Kardelis K, Pajaujiene S. Muscle size satisfaction and predisposition for a health harmful practice in bodybuilders and recreational gym users. Medicina 2007;43(4): 338-46.

3. Pope HG Jr, Kanayama G. Bodybuilding's dark side: Clues to anabolic steroid use. Current Psychiatry 2004;3(12):1-8.

4. Phillips KA. The presentation of body dysmorphic disorder in medical settings. Primary Psychiatry 2006;13(7):51-59.

5. Pope HG Jr, Katz DL, Hudson JI. Anorexia nervosa and reverse anorexia among 108 male bodybuilders. Compr Psychiatry 1993;34:406-09.

6. Pope HG Jr, Grubber AJ, Choi P, Olivardia R, Phillips KA. Muscle dysmorphia: An under-recognized form of body dysmorphic disorder. Psychomatics 1997;38:548-57.

7. Ebbeck V, Watkins PL, Concepcion RY, Cardinal BJ, Hammermeister J. Muscle dysmorphia symptoms and their relationships to self-concept and negative affect among college recreational exercises. J Appl Sports Psychol 2009;21: 262-75.

8. Phillips KA, Dufresne RG Jr. Body dysmorphic disorder: A guide for primary care physicians. Am J Clin Dermatol 2002;1: 235-43.

9. Pope CG, Pope HG, Menard W, Fay C, Olivardia R, Phillips KA. Clinical features of muscle dysmorphia among males with body dysmorphic disorder. Body Image 2005;2(4): 395-400.

10. Phillips KA, Wilhelm S, Koran LM, Didie ER, Fallon BA, Feusner J, et al. Body dysmorphic disorder: Some key issues for DSM-V. Depression and Anxiety 2010;27:573-91.

11. Gorgon S. Body image: Understanding body dissatisfaction in men, women and children (2nd ed). London and New York: Routledge Taylor and Francis Group 2008.

12. Leit RA, Gray JJ, Pope HG Jr. The media's representation of the ideal male body: A cause for muscle dysmorphia? Int J Eating Dis 2002;31(3):334-38.

13. Walker DC, Anderson DA, Hildebrandt T. Body checking behaviors in men. Body Image 2009;6:164-70.

14. Chung, Bryan. Muscle dysmorphia: A critical review of the proposed criteria. Perspectives Biol Med 2001;44(4):565-74.

15. Cafri G, Olivardia R, Thompson JK. Symptoms characteristics and psychiatric comorbidity among males with muscle dysmorphia. Compr Psychiatry 2008;49:374-79.

16. Borkoles E, Polman R, Levy A. Type-D personality and body image in men: The role of exercise status. Body Image 2010;7: 39-45.

17. McCreary DR, Saucier DM, Courtenay WH. The drive for muscularity and masculinity: Testing the associations among gender-role traits, behaviors, attitudes and conflicts. Psychology Men Masculinity 2005;6(2):83-94.

18. Barrett PT, Petrides KV, Eysenck SBG, Eysenck HJ. The Eysenck personality questionnaire: An examination of the factorial similarity of P, E, N and L across 34 countries. Personality Individual Differences 1998;25:805-19.

19. Kampen DV. Personality and psychopatholog: A theory based revision of Eysenck's PEN model. Clin Pract Epidemiol Ment Health 2009;5:9-21.
20. Olivardia R, Pope HG Jr, Hudson JI. Muscle dysmorphia in male weight lifters: A case-control study. Am J Psychiat 2000; 157:1291-96.

21. Jain K. Muscularity and its ramifications: Mimetic male bodies in Indian mass culture. South Asia 2001;24:197-224.

22. Rhea DJ, Lantz CD, Cornelius AE. Development of the muscle dysmorphia inventory. J Sports Med Phys Fitness 2004;44: 428-35.

23. Baghurst T, Lirgg C. Characteristics of muscle dysmorphia in male football, weight training and competitive natural and nonnatural bodybuilding samples. Body Image 2009;6:221-27.

24. Lane AM, Milton KE, Terry PC. Personality does not influence exercise-induced mood enhancement among female exercisers. J Sports Sci Med 2005;4:223-28.

25. Ryan TA, Morison TG. Psychometric properties of the muscle appearance satisfaction scale among Irish and British Men. Body Image 2010;7:246-50.

26. Olivardia R. Mirror, mirror on the wall, who's the largest of them all? The features and phenomenology of muscle dysmorphia. Harvard Rev Psychiatry 2001;9:254-59.

27. Leone JE, Sedory EJ, Gray KA. Recognition and treatment of muscle dysmorphia and related body image disorders. J Athl Train 2005;40(4):352-59.

28. Grieve FG. A conceptual model of factors contributing to the development of muscle dysmorphia. Eating Dis 2007;15(1): 63-80.

29. Mosley PE. Bigorexia: Bodybuilding and muscle dysmorphia. Europ Eat Dis Rev 2009;17(3):191-98.

30. Choi PYL, Pope HG Jr, Olivardia R. Muscle dysmorphia: A new syndrome in weightlifters. Brit J Sports Med 2002;36:375-77.

31. Hitzeroth V, Wessels C, Zungu-Dirwayi N, Oosthuizen P, Stein DJ. Muscle dysmorphia: A South African sample. Psych Clin Neurosci 2001;55:521-23.

32. Behar R, Molinari D. Muscle dysmorphia, body image and eating behaviors in two male populations. Rev Med Chile 2010;138: 1386-94.

33. Colley A, Roberts N, Chipps A. Sex role identity, personality and participation in team and individual sports by males and females. Int J Sports Psychol 1985;16:103-12.

34. Pimenta AM, Sanchez-Villegas A, Bes-Rastrollo M, Lopez CN, Martinez-Gonzalez MA. Relationship between body image disturbance and incidence of depression: The SUN Prospective Cohort. BMC Public Health 2009;9(1):1-9.

35. Ledwidge B. Run for your mind. Aerobic exercise as a means of alleviating anxiety and depression. Can J Behav Sci 1980;12: 126-40.

36. Raevuori A, Keski-Rahkonen A, Bulik CM, Rose RJ, Rissanen A, Kaprio J. Muscle dissatisfaction in young adult men. Clin Pract Epidemiol Ment Health 2006;2:6.

37. Hurst R, Hale B, Smith D, Collins D. Exercise dependence, social physique anxiety, and social support in experienced and inexperienced bodybuilders and weightlifters. Brit J Sports Med 2000;34:431-35.

38. Yadav K, Krishnan A. Changing patterns of diet, physical activity and obesity among urban, rural and slum populations in North India. Obesity Reviews 2008;9:400-08.

39. Daniel CR, Prabhakaran D, Kapur K, Graubard BI, Devasenapathy N, Ramakrishnan L. A cross-sectional investigation of regional patterns of diet and cardiometabolic risk in India. Nutr J 2011;10:12.

40. Kanayama G, Pope HG. Gods, men and muscle dysmorphia. Harvard Review Psychiatry 2011;19:95-98. 
41. Jackson CJ, Furnham A, Forde L, Cotter T. The structure of the eysenck personality profiler. Brit J Psychol 2000;91: 223-39.

42. Sandhu JS, Aggarwal S, Shenoy S, Sharma P. Influence of physical activity on the changes in personality traits and motor skills with age. Int J Sports Sci Phys Educ 2010;1:8-14.

\section{ABOUT THE AUTHORS}

\section{Jaspal Singh Sandhu (Corresponding Author)}

Professor, Department of Sports Medicine and Physiotherapy Guru Nanak Dev University, Amritsar, Punjab, India, e-mail: jssandhudr@gmail.com

\section{Sai Kishore}

Research Fellow, Department of Sports Medicine and Physiotherapy Guru Nanak Dev University, Amritsar, Punjab, India

\section{Shweta Shenoy}

Associate Professor, Department of Sports Medicine and Physiotherapy, Guru Nanak Dev University, Amritsar, Punjab, India

\section{Harwinder Singh Randhawa}

Director of Sports, Department of Physical Education, Guru Nanak Dev University, Amritsar, Punjab, India 